IP Periodica Polytechnica

Mechanical Engineering

\author{
57(2), pp. 3] 2013 \\ DOI: $10.3311 / P$ Pme.7039 \\ Creative Commons Attribution (i) \\ RESEARCH ARTICLE
}

\section{End-plate for noise-by-flow control in axial fans}

\author{
Alessandro Corsini, Anthony G. Sheard
}

Received 2013-03-29, accepted 2013-06-30

\begin{abstract}
The paper presents a design procedure for anti-vortex endplates that are fitted to tip limited blades of the subsonic axial fans utilised in compact cooling units. The authors study the impact of tip leakage vortex bursting on the performance of the studied class of fans. The vortex breakdown occurs in the swirling flows at a blade's tip, and is found to be a flow feature associated with the production of fan acoustic emissions. The link between aerodynamic flow features in the blade tip region and fan acoustic emissions is exploited through a design process that aims to control the blade tip flow with the specific objective of reducing fan acoustic emissions. This noise-by-flow flow control design process is implemented by reconfiguring the end-plate at the blade tip using a multiple-vortex-breakdown criterion for the design of the end-plates. The aerodynamic and acoustic performance of the newly conceived end-plate design has been assessed and is compared with the performance of a fan with blades fitted with base-line end-plate geometry. The assessment of aerodynamic and acoustic performance utilises both numerical simulations of the flow-field in the blade tip region plus an experimental assessment of fan aerodynamic and acoustic performance. The reported research verified the technical merit of the developed passive noise control strategy, demonstrating that the control of blade tip leakage flow can result in a reduction in blade tip flow generated noise.
\end{abstract}

\section{Keywords}

Passive noise control · end-plates · tip leakage-vortex breakdown $\cdot$ axial fans

\footnotetext{
Alessandro Corsini

Department of Mechanical and Aerospace Engineering, Sapienza University of Rome, Via Eudossiana, 18, I00184, Italy

e-mail: alessandro.corsini@uniroma1.it
}

\section{Anthony G. Sheard}

Fan Technology, Flakt Woods Ltd, Axial Way, Colchester, Essex, C04 5ZD, UK e-mail: geoff.sheard@flaktwoods.com

\section{Introduction}

The European Union Directive 327 mandates minimum fan and motor efficiency a grade (FMEG's) for industrial fans, with “Tier 1" FMEG's becoming legally binding on January $1^{\text {st }} 2013$ [1]. The minimum FMEG's will increase again on January $1^{\text {st }}$ 2015 following which the Commission will commence a review of the Regulation and its impact, and then make a decision on future increases in the minimum FMEG's. This regulatory framework has driven industrial fan manufacturers towards computational methods in an on-going effort to increase fan efficiency. In parallel to the regulatory framework intended to drive improvements in efficiency, market requirements are driving industrial fan manufacturers to reduce fan noise. Increasingly stringent acoustic requirements are a consequence of a requirement to install industrial fans in close proximity to populated areas. The regulatory and market requirements combine into a requirement for improved design methodologies that will deliver both higher efficiency and as a consequence of minimising or eliminating the aerodynamic origins of acoustic noise sources, lower noise industrial fan designs.

The aerodynamic origin of an industrial fans acoustic emission occurs as a consequence of one of two primary mechanisms, interaction and self-generated. Interaction noise occurs as a consequence of rotating components passing static components. Self-generated noise occurs as a consequence of unsteady aerodynamic blade loads [2,3]. Within industrial fans interaction noise is typically less significant than self-generated noise. Self-generated noise is driven by turbulent inflow, turbulent boundary layers, separated flow, trailing edge flow from blunt trailing edges, secondary flows and blade tip leakage flow [4].

When studying the aerodynamic origins of self-generated noise, Akaike et al. [5] observed that the vortical structure near the rotor tip in industrial fans is a dominant noise generating mechanisms. In his pioneering work, Longhouse [6] introduced rotating shrouds attached to the rotor tips to reduce tip leakage vortex noise. He concluded that the vortical flow near the blade tip has a dominant effect on both a fans acoustic emissions and aerodynamic characteristics. Inoue and Kuroumaru [7], Storer 
and Cumpsty [8] and Lakshminarayana et al. [9] all studied the impact of tip leakage flow on compressor aerodynamics, concluding that the three-dimensional and unsteady nature of the tip leakage flow had a primary impact on both noise generated and aerodynamic loss. Within the context of low-speed turbomachinery, tip leakage noise is generally correlated with the broadband spectral signature [6, 10,11]. Kameier and Neise [11] highlighted that, in addition to its effect on broadband noise, tip leakage flows can be responsible for narrowband tones at frequencies below the blade passing frequency that coincidence with a tip vortex rotational frequency.

During the last two decades, noise control has emerged as a new research field [12,13]. The scholars working in this field have proposed numerous noise reduction strategies that may be broadly categorised as passive, active or reactive. Recent research programmes have focused on the development of fan designs that aim to minimise noise-by-flow control. The flow control is achieved by incorporating passive or active flow control technologies. An example of a passive flow control technology is the chevron mixer for jet noise reduction [14]. An example of an active flow control technology is trailing edge blowing [15]. When considering how to classify noise-by-flow control technologies Thomas et al. [13] and Joslin et al. [16] base classification on the nature of the linkage between the underlying flow physics and the noise generation mechanisms.

The noise control techniques adopted by industrial fan manufactures are primarily passive, exploiting a direct linkage between fan geometry and flow features associated with specific noise sources. Those researchers who have studied the application of passive noise control techniques in industrial fans have primarily focused on blade and casing geometry, with the objective of controlling flow features associated with specific noise sources without sacrificing aerodynamic performance. The blade tip leakage flow has long been known as both a dominant noise source and a flow feature that reduces aerodynamic performance, and consequently passive noise control techniques that focus on reducing the magnitude of tip leakage flows have the potential to both reduce noise and improve aerodynamic performance. In an attempt to improve compressor performance researchers first experimented with casing treatments in the early 1970s utilising grooves [17, 18], or stepped gaps in the blade tip region [19]. These casing treatments improved the compressors stable operating range by reducing the intensity of blade tip leakage flow. Industrial fan manufactures have historically favoured a different approach to the casing treatments favoured by compressor designers, instead utilising annular rings of recirculating vanes over the leading edge of blades to stabilise fan performance [20].

While studying the performance of a small industrial fan Quinlan and Bent [21] were able to demonstrate that blade tip anti-vortex appendages were an effective passive noise control technology [20, 22,24]. Akturk and Camci [25] reported on a novel tip platform extension experimental study the resulted in more efficient fan with improved acoustic performance as a consequence of the control of flow swirl. Akturk and Camci [25] applied the their developed flow control methodology to the control of tip leakage flow in ducted lift fans for vertical take-off and landing applications [26,27]. Corsini et al. [28,29] and Bianchi et al. [31,32] investigated the application of profiled end plates to the blade tips of a family of compact cooling fans, advocating the link between blade tip leakage flow and vortex swirl control [28, 29].

The present paper presents a novel concept and a design procedure derived from the concept for blade tip end-plate design of subsonic axial fan blades. As a consequence of the role that organised structures in turbulent flow play in the noise generation process, controlling these structures is a key objective in noise suppression [30]. Experimental and numerical studies have demonstrated the reduction in fan noise that results from adopting tip leakage flow control technologies [31--33], were the authors speculated on the role of blade tip leakage vortex bursting on an industrial fan's aerodynamic and acoustic performance. As when controlling the swirling flows in the tip region of an aircraft wing [34] or in combustor technologies [35], the proposed design procedure rationale advocates linking blade tip end-plate geometry and the tip leakage vortex near-axis swirl to control the blade tip vortex and in so doing avoid the vortex bursting [36, 37].

This noise-by-flow control design procedure is implemented by reconfiguring the blade tip end-plate and in so doing influencing the momentum transfer from the leakage flow. The procedure also forces some waviness in the leakage vortex trajectory, as in delta-wing planforms [38]. The design procedure deliberately varies the blade tip end-plate thickness to control the leakage vortex rotation number's chord-wise evolution. The design procedure utilises a critical minimum value of the blade tip leakage vortex rotation number [40] and in so doing induces a sequence of augmentation-diminution of momentum transfer to the tip vortex up to near-critical swirl conditions [41,42]. In so doing the new blade tip end-plate design procedure results in the passive control of blade tip vortex swirl level, based on a succession of breakdown or bursting conditions. By avoiding bursting of the blade tip vortex the resultant blade tip end-plate produces lower acoustic emissions from the blade tip vortex, and consequently lower far-field fan noise [40].

The objective if the presented research is to establish the technical merit of the new blade tip end-plate design procedure, and its potential to reduce far-field fan noise. Section two describes the studied family of fans. Section three reviews the rationale of the end-plate thickness distribution concept and resultant design procedure. Section four presents a comparative assessment of the end-plate aerodynamic performance by studying the results of a numerical prediction of the flow-field at the blade tip region plus experimentally determined overall fan aerodynamic and acoustic performance. The primary conclusions of the reported research are summarised in section five. 
Tab. 1. AC $90 / 6$ fan family specifications. Datum blade geometry and rotor specifications

\begin{tabular}{ccc}
\hline & AC90/6 datum fan & \\
\hline$\ell / t$ & hub & Tip \\
\hline blade geometry & 1.32 & 0.31 \\
stagger angle (deg) & 54 & 62 \\
camber angle (deg) & 46 & 41 \\
\hline fan rotor & 6 & \\
blade count & 28 & \\
pitch angle at the tip $(\mathrm{deg})$ & 200.0 & \\
hub diameter $D_{h} \mathrm{~mm}$ & & \\
& 900.0 \\
casing diameter $D_{c}(\mathrm{~mm})$ & 950 \\
rotor tip clearance $\tau(\% \mathrm{span})$ &
\end{tabular}

\section{Cooling Axial Fans}

The reported research was conducted on a family of commercially available cooling fans. The studied fan, coded AC90/6, datum configuration incorporates a six-blade un-swept rotor, with modified ARA-D profile aerofoils blade, Tab.1. The bladepitch angle may be set during final assembly to customise the fan to a desired duty point. A direct coupled-induction 400-volt (AC), 3-phase motor was used to drive the rotor at a constant speed of $950 \mathrm{rpm}$, resulting in a blade tip was of $44.7 \mathrm{~m} / \mathrm{s}$ and a blade-passing frequency (BPF) of $99 \mathrm{~Hz}$.

The fan datum AC90/6 features a peak pressure rise of approximately $300 \mathrm{~Pa}$ at a flow rate of $5 \mathrm{~m}^{3} / \mathrm{s}$, with a design pressure rise of point of $270 \mathrm{~Pa}$ at a flow rate of $7 \mathrm{~m}^{3} / \mathrm{s}$, Fig. 1 The selected blade angle for both fan datum AC90/6 and variants of the fan with modified blade tip features was 28 degrees, measured as is customary in the industrial fan industry in the peripheral direction. A blade angle of 28 degrees was selected to ensure that the fan blades were highly loaded. Highly loaded blades suffer more sever degradation in both aerodynamic and acoustic performance as a consequence of the intensity of blade tip leakage vortex.

\section{Multiple Vortex Breakdown concept}

Breakdown of the blade tip leakage vortex is an important phenomenon within swirling flows. The breakdown constitutes a noise source, and consequently the link between blade tip flow and fan noise have been a subject of interest to scholars for the last two decades. The subject has historically been an active research area for aeronautical engineers [34] and combustion engineers [35], and today is being studied by researchers working within the industrial fan community [36, 37].

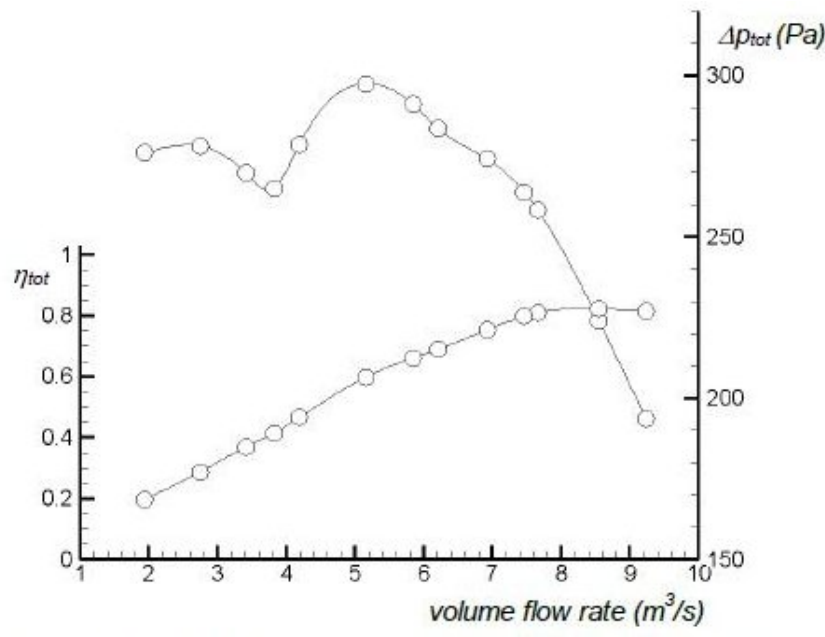

Fig. 1. Total pressure and total efficiency characteristic curves for the datum AC90/6 fan, with a blade angle of 28 degrees

\subsection{Background studies on tip end-plates}

Corsini and Sheard [28] and Corsini et al. [29,33] recently assessed the pay-off associated with the development of blade tip end-plate technology. The technology was originally developed for application to the blades of the industrial fan AC90/6, the $d a$ tum fan in the research reported in this paper. When fitted with a constant thickness blade tip end-plate the fan was designated AC90/6/TF. While studying the fan AC90/6/TF fan Corsini and Sheard [28] and Corsini et al. [29, 33] were able to isolate the aerodynamic flow mechanisms associated with reduction in fan acoustic emissions relative to the fan datum AC90/6.

One of the primary finding of Corsini et al. [33] when studying the fan AC90/6/TF was that the leakage flow control associated with the constant thickness blade tip end-plate resulted in the bursting of the blade tip leakage vortex. Corsini et al. [33] 
Tab. 2. Overall aerodynamic and acoustic performance of fans at $6 \mathrm{~m}^{3} / \mathrm{s}$

\begin{tabular}{lllll}
\hline & AC/90/6/TF fan & \multicolumn{3}{l}{$A C / 90 / 6 /$ TFvte fan } \\
\hline Aerodynamic [43] & $\Delta p_{\text {tot }}(\mathrm{Pa})$ & $\eta_{\text {tot }}$ & $\Delta p_{\text {tot }}(\mathrm{Pa})$ & $\eta_{\text {tot }}$ \\
& & & & \\
\hline & 291.4 & 0.66 & 299.2 & 0.68 \\
\hline Acoustic @ 2 m [43] & un-weighted & A-weighted & un-weighted & A-weighted \\
& $S W L$ & $S W L$ & $S W L$ & $S W L$ \\
& $d B$ & $d B(A)$ & $d B$ & $d B(A)$ \\
\hline & 92.2 & 87.1 & 91.7 & 87.6 \\
\hline
\end{tabular}

Fig. 2. Background on improved tip concepts, a) end-plate geometries, and b) chord-wise evolution of tip leakage vortex Rossby number line-circle: datum fan; dashed line, TF fan; dash-dotted line: TFvte fan
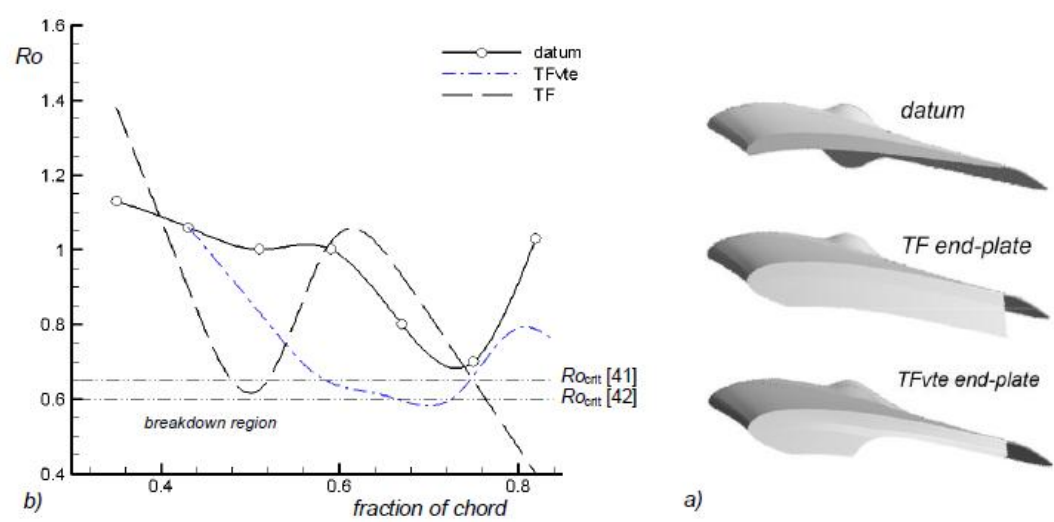

a) went on to study a further variation of the blade tip end-plate with variable thickness. This variable thickness blade tip endplate was designated AC90/6/TFvte.

The evolution of the tip leakage vortex swirl level along the chord may be expressed in terms of the Rossby number Ro, following the method of Ito et al. [43]. The Rossby number distributions for the fan datum AC90/6, AC90/6/TF and AC90/6/TFvte, Fig. 2, indicates that the fan AC90/6/TF features a vortex breakdown at a Rossby number within a critical range or Rossby number Uchida et al. [41] associated with the breakdown of axi-symmetric vortex and Garg and Leibovich, [42] with the breakdown of wing tip vorticies.

The aerodynamic and acoustic impact of the blade tip leakage vortex not bursting is illustrated in Tab. 2. Acoustic performance was assessed in accordance with the requirements BS 848-2.6:2000, 2000, ISO 10302:1996 [44]. The adoption of variable thickness blade tip end-plate resulted in improved pressure rise and efficiency, improvements that may be attributed to control of the blade tip leakage vortex. This aerodynamic improvement was off-set by a higher sound A-filtered sound power level [45]. This increase in fan noise may be attributed to an increase in the intensity of the blade tip leakage vortex, from which we may conclude that blade tip leakage vortex intensity and stability both contribute to acoustic emissions from the blade tip region.

\subsection{Rationale and design criterion}

The objective of the reported research is development of a design process that links blade tip end-plate design with flow control and in so doing attenuation of fan noise. This noise-by-flow control is achieved by designing the blade tip end-plate to control the chord-wise evolution of the tip leakage vortex Rossby number. The resulting blade tip end-plate design induces sequences of augmentation-diminution of momentum transfer to the tip leakage vortex up to a near-critical Rossby number [40]. The design process exploits a correlation between the blade tip end-plate thickness $t_{e p}\left(s_{c}\right)$, the tip leakage vortex kinematics, the local blade loading and the magnitude of the blade tip leakage flow. The resultant end-plate thickness $t_{e p}\left(s_{c}\right)$ is derived from the tip leakage vortex Rossby number $R o$, with the twin objectives being maintenance of a stable vortex that does not burst and minimum vortex intensity.

The derivation of blade tip end-plate geometry follows the method of Spall et al. [34], who proposed scale definitions for the blade tip velocity distribution consistent with swirling flows, leading-edge vortices, and unconfined trailing wing-tip vortices. Spall's et al.'s [34] method was interpreted in the present study within the context of axial decelerating turbomachinery and consequently the definition for Rossby number of a confined tipleakage vortex may be expressed as:

$$
R o=\frac{V}{r \Omega},
$$

where: $\mathrm{r}$ is defined as the radial distance from the vortex axis at which the swirl velocity is a maximum, in accord with the 
Fig. 3. Leakage flow coordinate system definitions

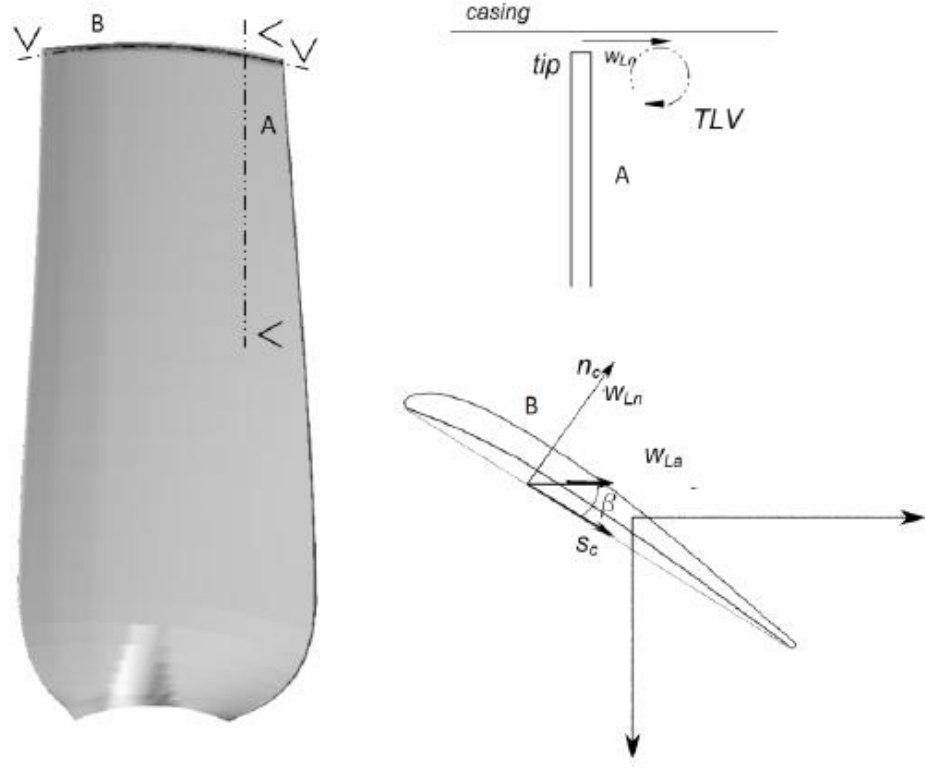

characteristic viscous length scale suggested by Leibovich [46]; $\Omega$ is defined as the rotation rate in the blade tip leakage vortices near the vortex centre); and $V=w_{L a}$, is defined as the axial velocity at $r$ consistent with the swirling velocity scale

$$
\Omega r=w_{L p}
$$

The algebraic function linking the end-plate thickness $t_{e p}\left(s_{c}\right)$ to the tip leakage vortex Ro number was extrapolated by using classical flow models for the tip clearance flow documented in experimental and theoretical studies on the flow in the blade tip region of axial flow compressors, fans and pumps [47, 48]. The proposed approach, though not mathematically precise, included all the dominant flow and blade parameters that influence the creation of vortex in the blade tip to casing gap and is in accord with fundamental physical principles.

The radial dimension of the tip leakage vortex $r$ was defined using Rains model of the leakage flow [47], which establishes a correlation among the scale of the vortex, the chord-wise position, the tip gap and the local blade load as:

$$
r\left(s_{c}\right)=0.14 \tau\left[\frac{s_{c}}{\tau} C_{l}^{0.5}\right]^{0.85},
$$

where, $s_{c}$ is the abscissa along the chord; $\tau$ is the tip gap height; and $C_{l}$ is the local lift coefficient.

The rotational velocity of the tip leakage vortex $\Omega$ was defined using Lakshminarayana's model [48], valid in incompressible flow and without taking into account the effects of blade rotation:

$$
\Omega\left(s_{c}\right)=\frac{(1-k) \Gamma}{2 \pi r^{2}},
$$

and,

$$
\begin{gathered}
\Gamma=0.5 C_{l} \ell_{c} V_{m}, \\
(1-k)=0.23+7.45\left(\frac{\tau}{s_{c}}\right),
\end{gathered}
$$

where, $\Gamma$ is the blade circulation; $\ell_{c}$ is the blade tip chord; and $V_{m}$ is the average velocity through the tip blade section which depends on the local incidence and deviation angles.

The velocity scale $V$, is approximated by introducing the leakage velocity component along the tip vortex axis $w_{L a}$ following the method of Corsini and Sheard [28]. Rains [47] concluded that the tip gap flow driven by the pressure gradient across the blade can be considered normal to the camber line of the blade, and therefore $w_{L a}$ can be defined as a function of leakage velocity normal to the blade chord $w_{L n}$ :

$$
V \approx w_{L a}=w_{L n} \sin \left(\beta_{L}\right)
$$

with $\beta_{L}$ being the angle between the leakage jet and the chord, Fig. 3. The leakage velocity $w_{L n}$ may therefore be derived by introducing a two-dimensional viscous analysis [48] as a function of the pressure gradient within the blade tip gap at each chordwise abscissae location $s_{c}$. The dependence of friction factor $f_{f}$ on the chord-wise position $s_{c}$ is fixed by use of a scaling value for the leakage flow bulk velocity $w_{L n}$ that in turn enables the velocity $w_{L n}$ to be defined as:

$$
w_{L n}\left(s_{c}\right)=\sqrt{\frac{2 \tau}{\rho f_{f}\left(\operatorname{Re}_{\text {gap }}\right) t_{e p}\left(s_{c}\right)} d p\left(s_{c}\right)},
$$

where, $f_{f}$ is the friction factor itself a function of leakage flow Reynolds number, $\operatorname{Re}_{g a p} ; \tau$, is the tip gap height; and $d p\left(s_{c}\right)$, is the static pressure drop through the tip gap.

Using the model defined in Eq. 5. we were able to derive a closure equation for a Multiple-Vortex-Breakdown (MVB) blade tip end-plate design that correlates the geometry of the end-plate with the evolution of blade tip vortex swirl, blade parameters and load conditions. By re-arranging the Eqs. (2), (3) and (6), the algebraic equation $t_{e p}\left(s_{c}\right)=f(R o)$ reads as:

$$
t_{e p}\left(s_{c}\right)=\mathfrak{J}_{\text {load }} \mathfrak{J}_{\text {geo }}\left[\frac{\sin \left(\beta_{L}\right)}{V_{m} \operatorname{Ro}\left(s_{c}\right)}\right]^{2} s_{c}^{z},
$$


Fig. 4. The MVB end-plate design. a.: Prescribed number (line-square: fan AC90/6/TF mvb, and b.: MVB blade geometry (not-to-scale) chord-wise evolution of tip leakage vortex Rossby

a)

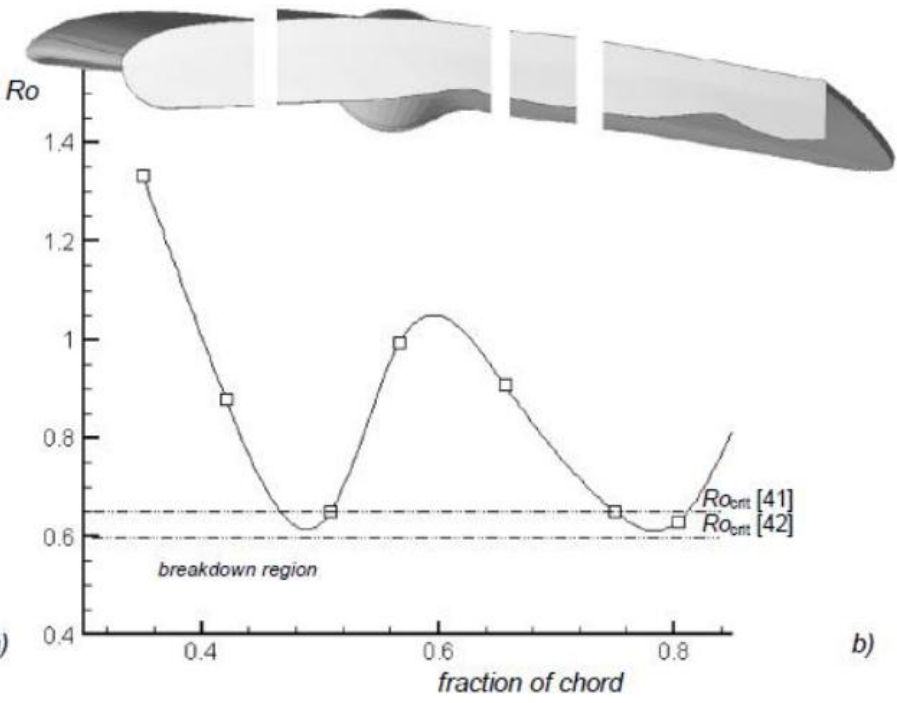

Fig. 5. The MVB end-plate design. Sensitivity analysis on the end-plate geometry $t_{e p}, s_{c}$ a the tip gap height $\tau$ and $\mathrm{b}$ the blade section lift $C_{l}$.
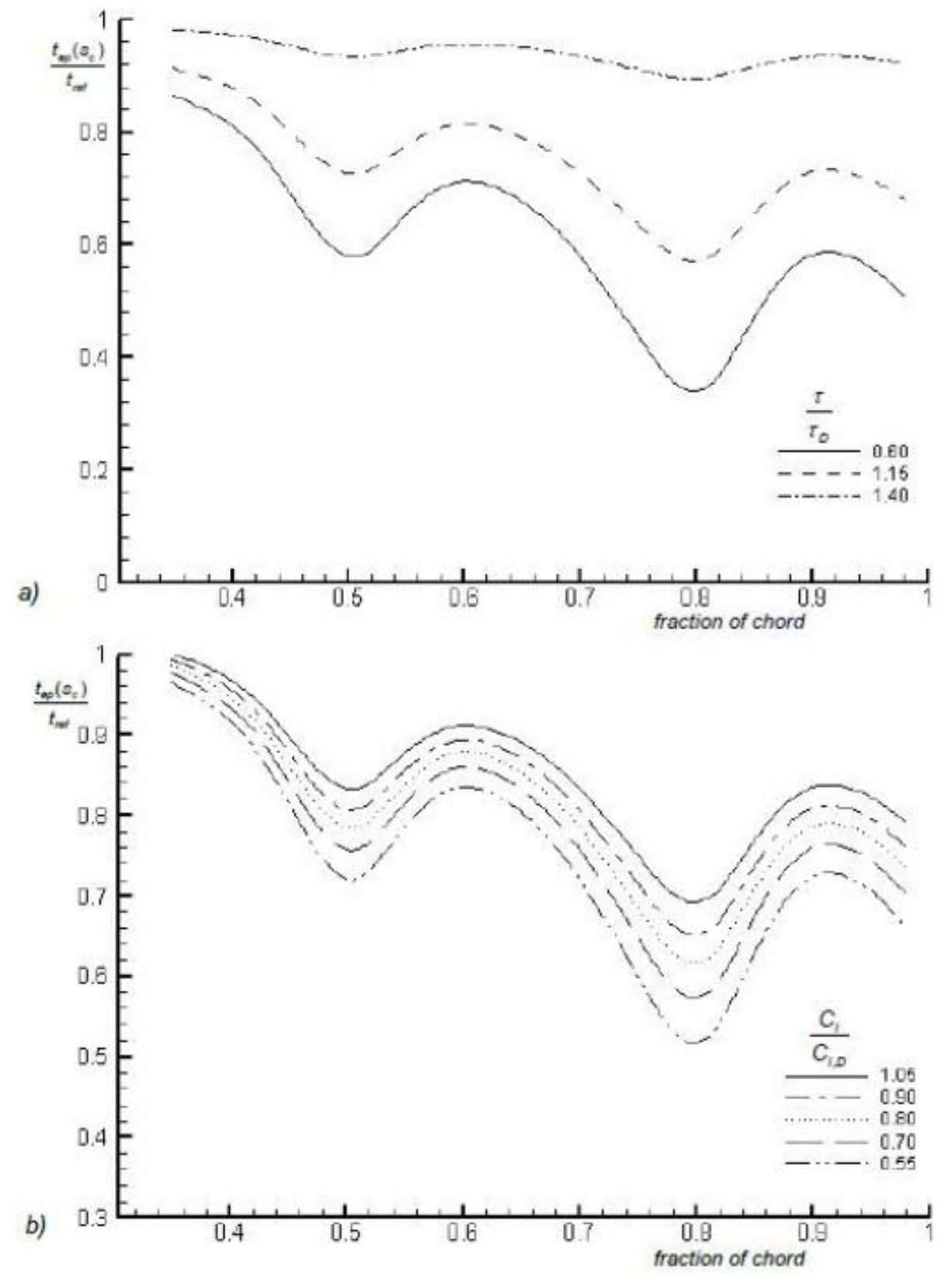
where $\mathfrak{J}_{\text {load }}$ and $\mathfrak{J}_{\text {geo }}$ are groups of parameters which describe, respectively, the influence of blade loading condition at the tip and blade geometry. Notably, In Eq. 7 the exponent $z$ is higher than unit.

Moreover, the target evolution of the swirl level of the tip leakage flow, i.e. $\operatorname{Ro}\left(s_{c}\right)$, is blade specific and, in the present study, has been derived by the numerical investigation of the datum fan configuration.

The MVB blade tip end-plate geometry results in a prescribed chord-wise distribution of the Rossby number against the endplate shape, Fig. 4. The MVB chord-wise thickness variation is a direct result of the developed design procedure, correlating swirl level of the main vortical structures over the blade tip with the end-plate geometry.

\subsection{Multiple-Vortex-Breakdown sensitivity analysis}

A sensitivity analysis of the MVB end-plate design identified the influence of blade tip to casing clearance $\tau$ and blade loading on blade tip feature thickness, Fig. 5. Blade tip to casing clearance was varied from 60 to 140 per cent of design value, $\tau_{D}$, and blade loading $C_{l}$ was varied from 55 to 105 per cent of design value, $C_{l, D}$. To this end, the local lift coefficient could be considered as a function of both the blade camber and the blade angular setting, i.e. the local pitch angle or its complementary the stagger angle. The MVB design procedure results in an increase in end-plate thickness when the momentum of tip leakage flow requires a diminution. The control of the tip leakage flow swirling could be required either because of an enlarged blade tip to casing gap or because of aerodynamically overloaded blade tip sections. When the relative influence of blade tip to casing clearance and blade loading are compared, clearance $\tau$ is the more dominant parameter. Increasing clearance to 140 per cent of its design value results in near uniform end-plate thickness, Fig. 5.

\section{Numerical survey of the end-plate aerodynamics}

\subsection{Methodology}

Numerical technique. The Reynolds-averaged NavierStokes equations were solved using an original parallel multigrid finite element flow solver [50], developed using $\mathrm{C}++$ technology and libMesh libraries [51]. The fluid dynamics of incompressible three dimensional turbulent flows in a rotating frame of reference was modelled with a topology-free low-Reynolds variant of a non-linear $\mathrm{k}-\varepsilon$ model [52, 53]. The finite element flow solver used second-order approximations in space for velocity-pressure and turbulent variables. The Navier-Stokes and scale-determining turbulence equations were solved fully coupled with a linear solver based on a preconditioned generalised minimal residual method (GMRES) algorithm.

Mesh and boundary conditions The mesh was built in a non-orthogonal body-fitted coordinate system by merging two structured h-type grid systems.

- (i) Mesh in the main flow region (surrounding the blade) and
- (ii) embedded with the tip gap region

For the datum AC90/6 fan the mesh consists of approximately 0.6 million linear hexahedral elements. The node distribution in the axial direction consisted of 20 per cent of nodes upstream of the blade leading edge, 50 per cent of nodes in the blade passage, and 30 per cent of nodes downstream of the blade passage. The blade tip to casing clearance was modelled using 13 cells. The computational grid had an adequate clustering towards the solid boundaries, with the ratio of minimum grid spacing on solid walls to mid-span blade chord being set at $2 \times 10^{-3}$ on the blade tip, casing wall, and blade surfaces. The grid refinement towards the solid surfaces controlled the dimensionless distance value to approximately 1 on the first nodes row.

Standard boundary condition settings were adopted [33, 54]. The Dirichlet conditions for the relative velocity components were imposed at the inflow section, half a mid-span chord upstream of the leading edge. The inlet velocity profile was obtained from flow simulation in an annular passage of the same hub-to-casing diameter ratio as the datum AC90/6 fan, with the simulation including an upstream spinner cone. The inlet distribution of turbulent kinetic energy $(k)$ was obtained from an axi-symmetric turbulence intensity profile featuring a nearly uniform value in the core region of approximately six per cent, which increased approaching the end-walls to approximately ten per cent. The inlet profile of turbulence energy dissipation was based on the length scale $\left(l_{\varepsilon}\right)$ set to 0.01 of rotor pitch at midspan. Flow periodicity upstream and downstream of the blading, and Neumann outflow conditions (homogeneous for $(k)$ and $\varepsilon$, and non-homogeneous for the static pressure), completed the boundary data.

\subsection{Flow survey at the blade tip}

The numerical analysis facilitated a study of the blade tip leakage vortex evolution at a near design flow rate of $7 \mathrm{~m}^{3} / \mathrm{s}$, Fig. 6. The normalized helicity $\mathrm{H}_{\mathrm{n}}$, based on the absolute vorticity, was used as the tip vortex swirl metric. Normalized helicity provides a criterion for the detection of vortex bursting [33,55]. Normalized helicity $\mathrm{H}_{\mathrm{n}}$ was defined and normalised as:

$$
H_{n}=\left(\xi_{i} \cdot w_{i}\right) /(|\xi||w|) \text { with } i=1, \ldots 3,
$$

where $\xi_{i}$ and $w_{i}$ are the Cartesian components of the absolute vorticity and relative velocity vectors, and $|\xi|$ and $|w|$ are their norms.

When the normalised helicity results for the datum AC90/6 fan are studied, Fig. 6a, it is apparent that the helicity field indicates that there is a chord wise vortical structure emanating from the first quarter of the blade chord that is highly skewed. This vortical structure co-exists with a weak tip separation vortex. Over the last quarter of the blade chord the leakage flow may be characterised by merging of the tip separation vortex and the leading edge vortex. This merging results in a unique clock-wise vortical structure that affects the blade to blade flow-field over the majority of the blade pitch in the tip region. 

age vortex cores: a.: fan datum AC90/6, b.: fan AC90/6/TF, c.: fan AC90/6/TFvte and d.: fan AC $90 / 6 / \mathrm{TF}$ mvb fan at the fans $6 \mathrm{~m}^{3} / \mathrm{s}$ design flow rate.
Fig. 6. Normalised helicity contours and leak-

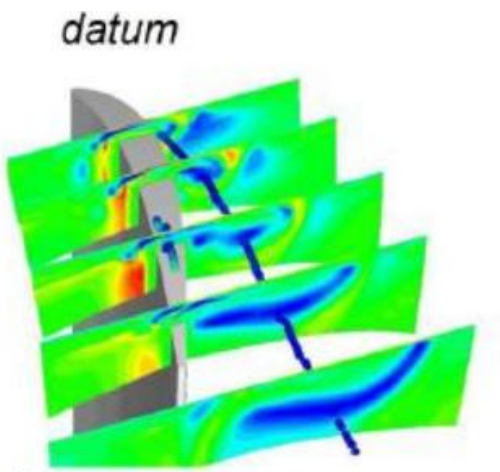

a)

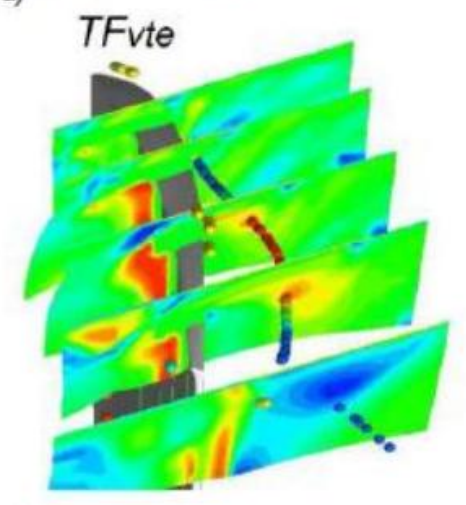

c)

Fig. 7. Tip leakage-vortex three-dimensional streamlines: a.: fan datum AC $90 / 6$, b.: fan AC90/6/TF, c.: fan AC90/6/TFvte and d.: fan $\mathrm{AC} 90 / 6 / \mathrm{TF}$ mvb fan at the fans $6 \mathrm{~m}^{3} / \mathrm{s}$ design flow rate.

a)

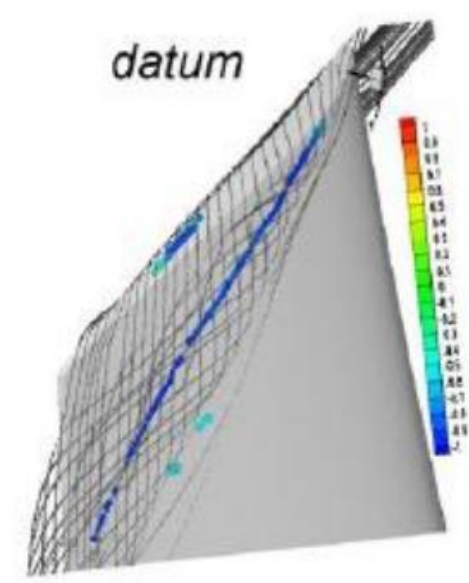

b)

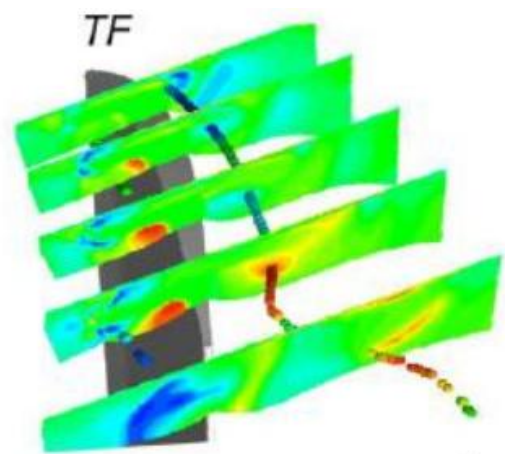

b)

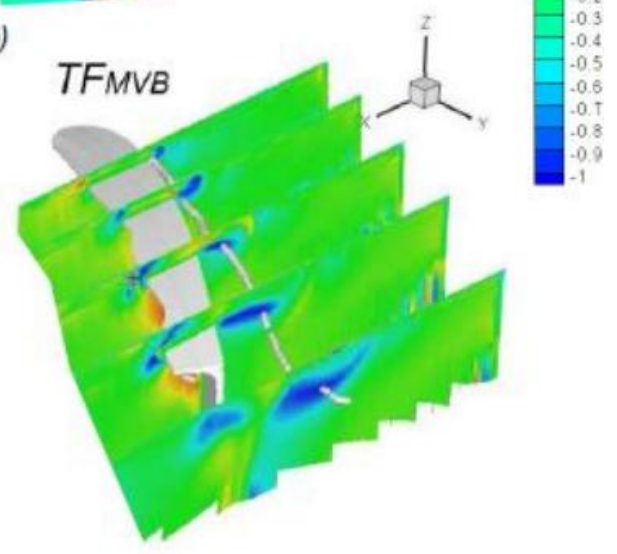

d)

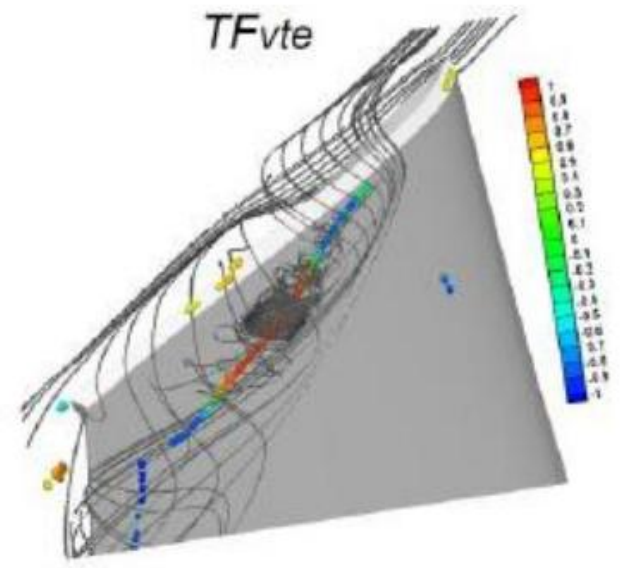

c)

d)

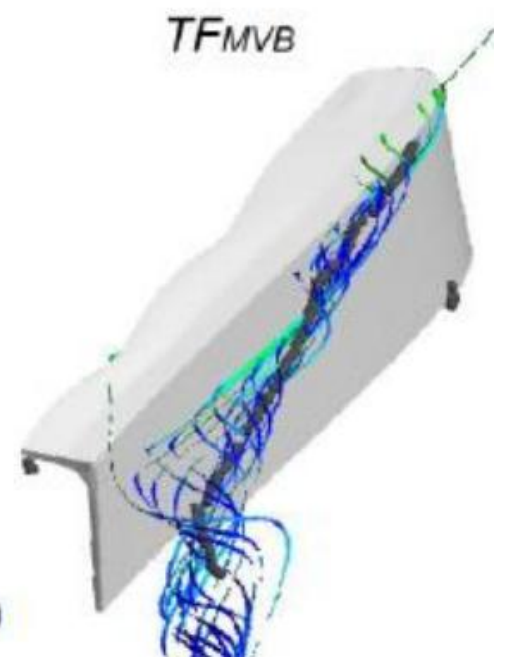

When the normalised helicity results for the fan AC90/6/TF are studied, Fig. 6p, it is apparent that the constant thickness end-plate induces a significant change in the blade tip leakage flow physics. The tip leakage vortex normalised helicity re- 
duces as the vortex travels from blade leading to trailing edge, and is deflected as a consequence of near-axis swirl weakening. Over the last quarter of the blade chord the tip leakage vortex collapses, producing a bubble-type separation that indicates vortex breakdown [28,33]. The separated flow evolves into a counter-clock wise vortex and immediately downstream of the rotor this vortex is washed-out and consequently no coherent vortical structure is evident.

When the normalised helicity results for the fan AC90/6/TFvte are studied, Fig. 6r, it is apparent that tapering the end-plate thickness shifts the origin of the primary vortical structure downstream in comparison to both the datum AC90/6 and AC90/6/TF blades. At mid-chord the AC90/6/TFvte reduction of end-plate thickness results in an increase in the energy of the primary vortical structure but additionally drives an anti-clockwise rotating cell from the blade pressure side that interacts with the primary vortical structure. This interaction indicates that the part-chord end-plate results in a blade tip flow-field that is distinctly different to that associated with both the datum AC90/6 and AC90/6/TF blades. The part-chord end-plate effectively blocks leakage flow over the front half of the blade chord, forcing the leakage flow to the rear half of the blade chord where the end-plate is tapered. This pressure gradient re-distribution is not considered in the proposed design concept that manages Rossby number above a critical value [28], a factor that is at least partly responsible for the noise performance of the AC90/6/TFvte fan.

When the normalised helicity results for the fan AC90/6/TFmvb are studied, Fig. 6d, it is apparent that the tip leakage vortex origin is located in the first quarter of the blade chord. In this regard the fan AC90/6/TFmvb is similar to the fan AC90/6/TF. The evolution of the normalised helicity contours indicates that the design procedure has produced an end-plate design that does result in flow control that both reduce leakage flow and overall vortical swirl. The normalised helicity contours indicate that tip vortex inception, evolution and convection through the blade passage is managed by a succession of leakage flow momentum enhancements and diminution. This momentum enhancements and diminution of the tip leakage vortex both minimises tip clearance flow rate and results in a vortical structure that does not burst.

The analysis of normalised helicity results may be complimented by an analysis of the tip leakage vortex streamlines, Fig. 7. Using the tip leakage vortex streamlines for the $d a$ tum AC90/6 fan as a benchmark for comparison, Fig. 7a, it is apparent that both the fan AC90/6/TF and fan AC90/6/TFvte (Fig. 7p and Fig. 7k) are affected by the presence of a bubblelike separation along the vortex axis. For the fan AC90/6/TF this separation occurs as a consequence of excessive leakage flow reduction. For the fan AC90/6/TFvte this separation occurs as a consequence of a leakage jet a mid-chord interacting with the tip vortex. When the tip leakage vortex streamlines for the fan AC90/6/TFmvb are studied, Fig. 7d, it is apparent that the flow control design procedure has resulted in an effective endplate. The re-circulating flow regions observable in both the fan AC90/6/TF and fan AC90/6/TFvte streamlines have been eliminated, and the tip vortex does not burst.

The vortex eduction analysis using Hn demonstrates that the presence of the end-plate planforms irrespective to their shape simplify the systems of vortical structure by letting emerge only main tip leakage vortex formations.

The analysis of normalised helicity and tip leakage vortex streamlines may be considered to be primarily an analysis of aerodynamic performance. This aerodynamic analysis must be complimented by a consideration of the acoustic consequence of the aerodynamic flow features identified. Changes in the blade tip flow-field will have acoustic consequences. The change in end-plate geometry may result in an increase in the acoustic energy associated with the flow features induced by the endplate or alternatively the sound absorption may increase as a consequence of acoustic waves traversing regions of turbulent flow [56]. When considering the impact of blade tip end-plates, the characteristic time scales associated with turbulent flow are significantly shorter than those associated with acoustic waves. Consequently we may assume that turbulence is both not influenced by the passage of acoustic waves and that the turbulence does not absorb acoustic energy. If it is accepted that acoustic energy generated by blade tip flow features is not absorbed within the blade passage, then it must also be accepted that acoustic energy generated by flow features in the blade tip region is transmitted to the fan-field.

In cases where the turbulence characteristic time scale is of the same order of magnitude of the sound time scale, acoustic energy of aerodynamic origin is damped as it propagates through regions of turbulent flow. The acoustic characteristics of industrial fans has been studied by Guedel [56] who concluded that turbulent shear layers result in sound absorption as a consequence of the rotation and stretching of vortical flow features passing though the turbulent shear layer. Before a comparative analysis of the four end-plate designs is possible, it is therefore necessary to establish if the flow-field in the blade tip region does, or does not absorb acoustic energy. A theoretical model for sound absorption in wall turbulent shear flows at low Mach numbers given by Howe [57] who concluded that if the turbulent scale-determining quantities are not influenced by the coherent perturbation velocity, the net dissipation of acoustic energy may be expressed as:

$$
\Pi=\rho_{0} v_{A}\left(\frac{\partial \bar{V}_{i}}{\partial x_{j}}\right)^{2},
$$

where, $\rho_{0}$ is the air density in normal condition, $\bar{V}_{i}$ is the vector of sound coherent perturbation velocity, $v_{A}$ is the coefficient of acoustic dissipation. According to Howe [57] this net dissipation of acoustic energy coefficient depends on the local viscosity of the fluid that may be expressed as:

$$
v_{A}=\left[2 v_{t}+v\right]
$$


Fig. 8. Coefficient of acoustic energy dissipation: a.: fan datum AC90/6, b.: fan AC90/6/TF, c.: fan AC90/6/TFvte and d.: fan AC90/6/TF mvb fan at the fans $6 m^{3} / s$ design flow rate.

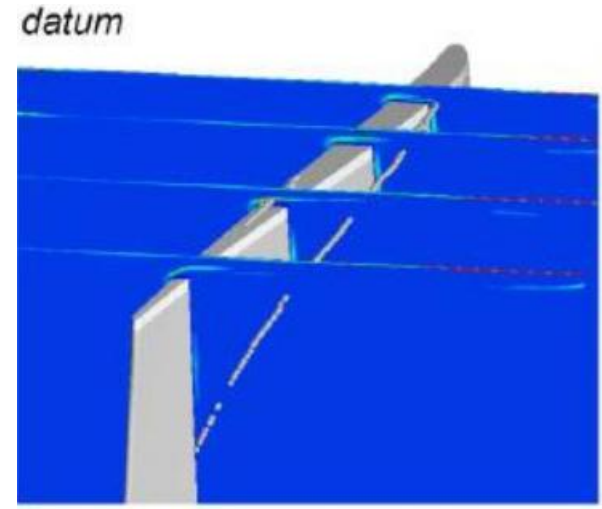

a)

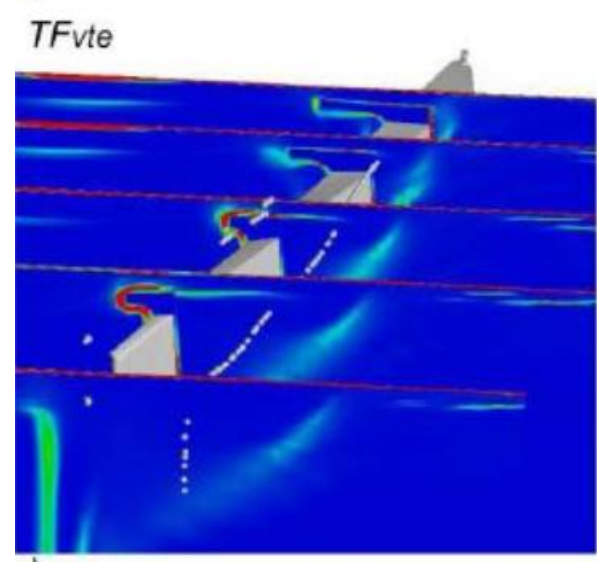

c)

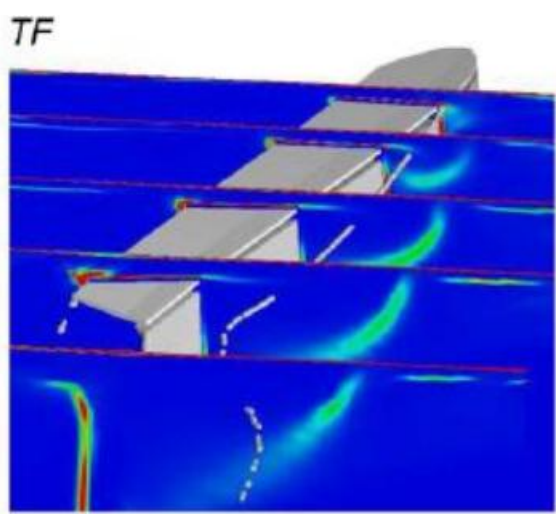

b)

\section{TFMVB}

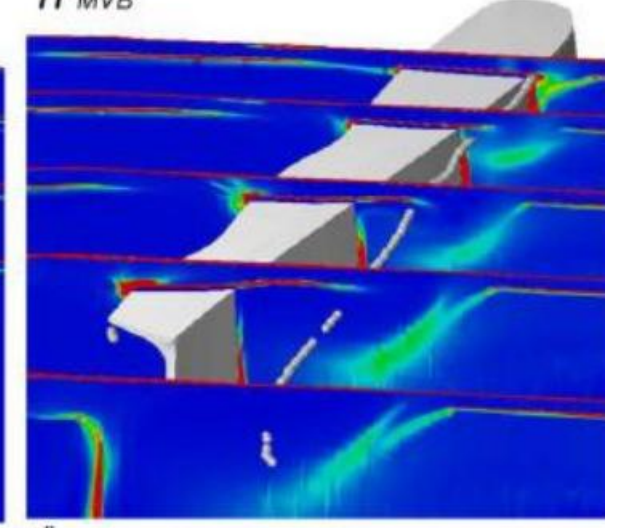

d) where, $v_{t}$ is the turbulence viscosity, and $v$ is the air kinematic viscosity.

Following the method of Howe [57] the previously presented aerodynamic analysis may be complimented by an analysis of the coefficient of acoustic energy dissipation, Figure 8. When the coefficient of acoustic energy dissipation results for the $d a$ tum AC90/6 fan are studied, Fig. 83, it is apparent that the tip leakage vortex development results in an inviscid swirling core, an observation that is self-consistent with the conclusions of other scholars [8, 54]. When the coefficient of acoustic energy dissipation results for the fan AC90/6/TF, fan AC90/6/TFvte and fan AC90/6/TFmvb are studied, Fig. $8 \mathrm{p}, 8 \mathrm{c}$ and 8d, a common theme attributable to all three end-plates is their role as mixing devices that affect the blade tip leakage flow [29]. All three endplates affect the ratio between axial and peripheral momentum transfer from the tip leakage vortex that in turn produces unstable structures. As a consequence the induced vortex instabilities manifest themselves as a loss of rotational coherence that may be related to a reduction in far-field fan noise.

\section{Experimental survey of the end-plate performance}

\subsection{Methodology}

\section{Aerodynamic test}

Measurements of static and dynamic pressure were carried out using a type B test rig, configured in accordance with the ISO5801 standard [44]. The performance measurements were derived from pressure measurement made using pressure trans- ducers equally spaced around the casing wall and a standard Pitot-probe. The Pitot-probe was mounted on a traversing mechanism fixed to the outer wall of the test rig. A digital multichannel micro-manometer with $2 \mathrm{kPa}$ range and a resolution of $1 \mathrm{~Pa}$ was used to read pressure data. The pressure measurements accuracy was $0.5 \%$ of read data. Fan efficiency was defined as the ratio between the air power (computed on either static or dynamic pressure rise) and the electric input power. The input electric power was measured with an AC power analyser with an accuracy of $0.24 \%$ of reading.

\section{Noise tests}

The acoustic measurements were conducted in an anechoic chamber originally developed for measuring industrial fan noise in accordance with the BS848-2.6:2000 standard [58], equivalent to the ISO 10302:1996 standard. The anechoic chamber cut-off frequency was $25 \mathrm{~Hz}$. A more complete description of the facility is given by Bianchi et al. [59]. The acoustic measurements were carried out using a type-A configuration with the fan installed downstream of an acoustically treated plenum chamber with a free outlet. The fan center line was two meters from the floor, in an arrangement similar to that typical of compact cooling fans when installed in-service. A bell-mouth was mounted on the fan inlet to give uniform and un-separated flow into the fan.

Far-field noise was measured at a distance of six fan diameters from the fan outlet, in accordance with the recommendations of 

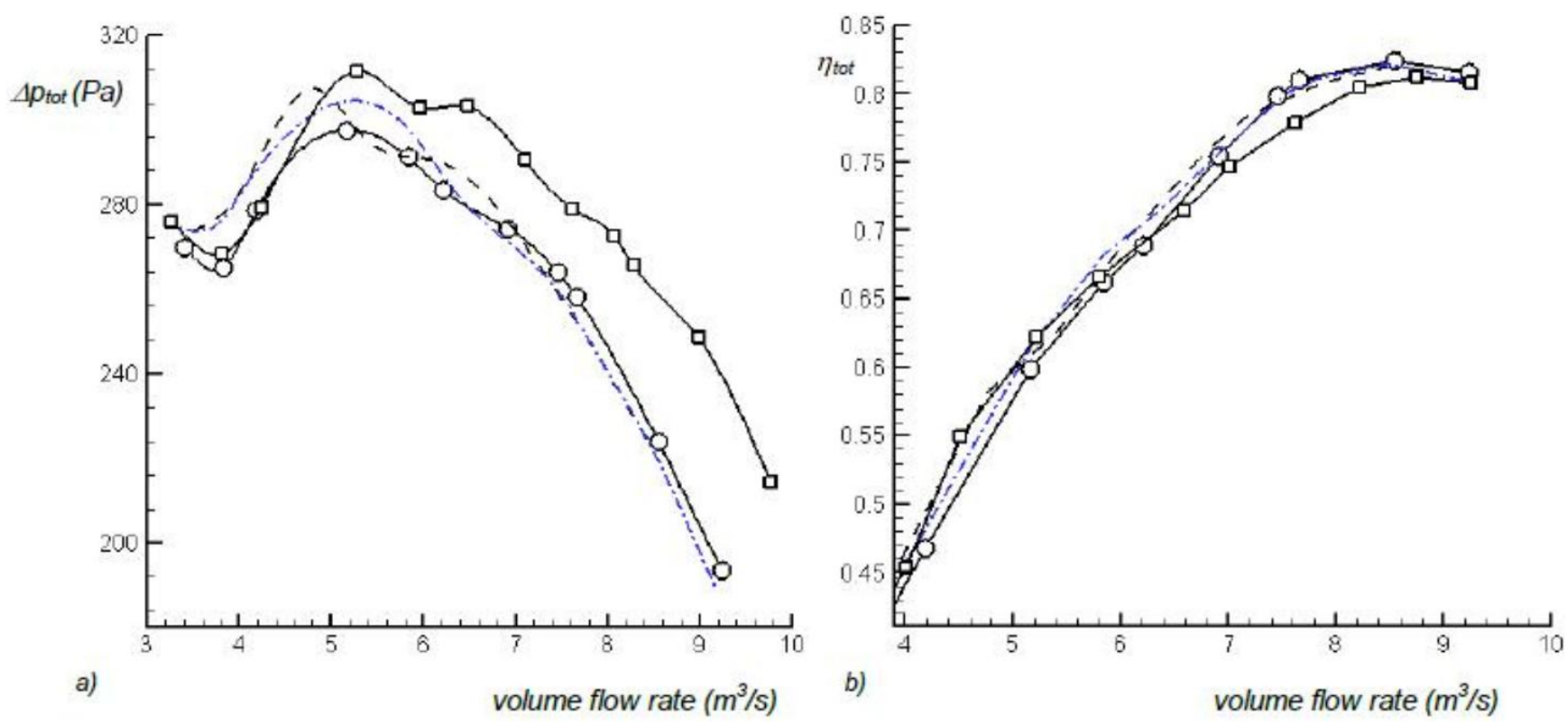

Fig. 9. Measured $a$ ) total pressure and $b$ ) total pressure efficiency characteristic curves.Line-circle: Fan datum AC90/6; dashed line, fan AC/90/6/TF; dash-dotted line: Fan AC/90/6/TFvte, line-square: fan AC/90/6/TF mvb fan
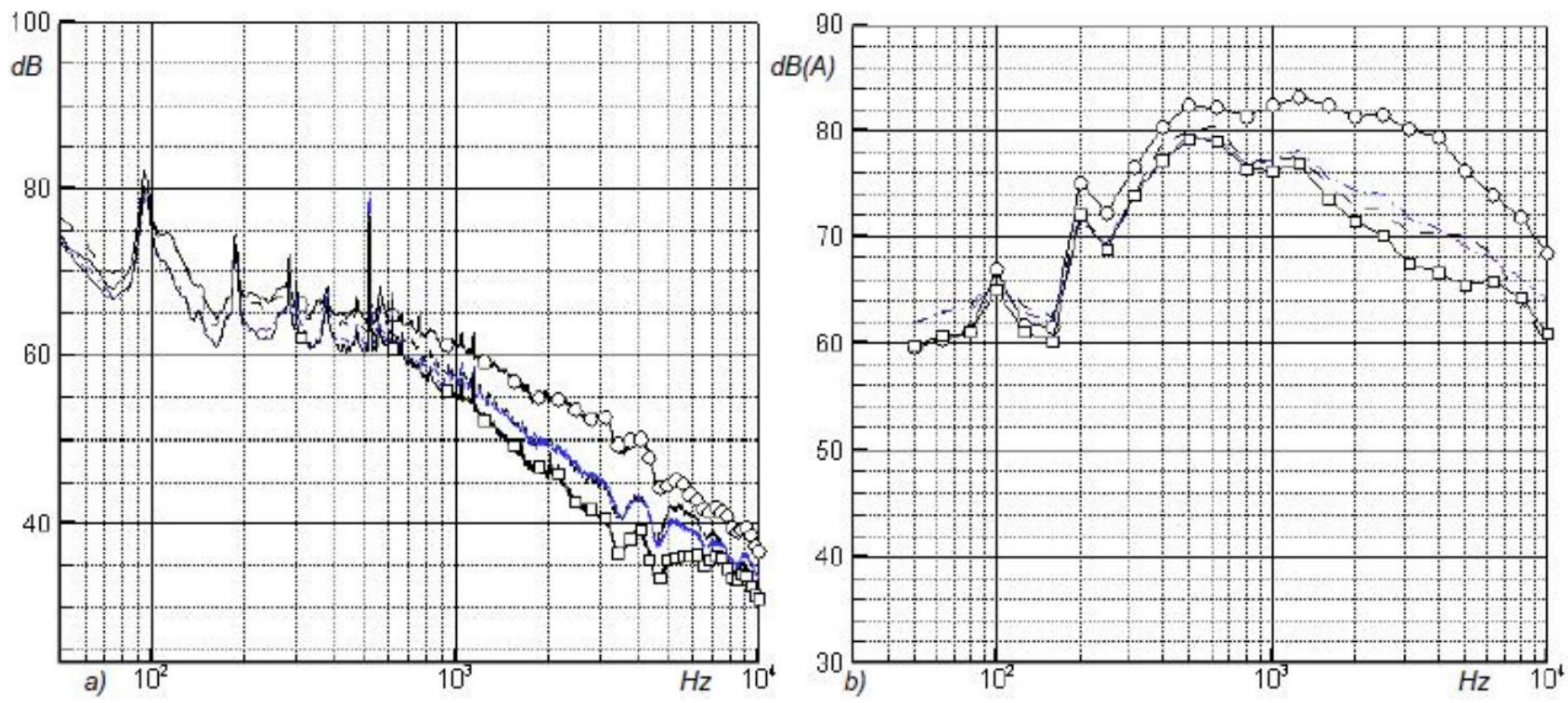

Fig. 10. Measured $a$ ) narrow-band spectra and $b$ ) A-filtered one-third octave band spectra. Line-circle: fan datum AC90/6; dashed line, fan AC/90/6/TF; dash-dotted line: fan AC/90/6/TFvte, line-square: fan AC/90/6/TF mvb fan

Leggat and Siddon [60]. Air-speed measurements at the location of the far-field microphone indicated a flow rate off less than one meter per second that may be considered low enough to have only a second order effect on the acoustic measurements made using the microphone. The free-field microphone was set at the same height as the fan centre line. In all cases, the signals were measured for 30 seconds, each measurement was repeated three times and the results averaged. The error in measured nose was estimated to be between $0.1-0.2 \mathrm{~dB}$ at $1 \mathrm{kHz}$. To isolate fan aerodynamic noise from motor noise, a preliminary test of the motor alone was conducted to establish its spectral signature that was then used to correct subsequent noise measurements.

\subsection{Aerodynamic performance}

The aerodynamic performance of the fans datum AC90/6, AC90/6/TF, AC90/6/TFvte and AC90/6/TFMVB was measured, Fig.9. An analysis of the total pressure rise characteristic curves indicates that the fan AC90/6/TFMVB performed significantly better than the other fans. The aerodynamic gain associated with the MVB end-plate was is approximately a 5 per cent increase in pressure at the $6 \mathrm{~m}^{3} / \mathrm{s}$ near-peak pressure condition and 7 per cent increase in pressure at the $\mathrm{d} 7 \mathrm{~m}^{3} / \mathrm{s}$ design condition. This improvement in pressure developing capability did not reduce the fan AC90/6/TFMVB stable operating range that was unchanged compared with the other fans. 
Tab. 3. Comparison of acoustic performance

\begin{tabular}{ccccccccc}
\hline \multicolumn{1}{c}{ AC/90/6 datum fan } & AC/90/6/TF fan & & \multicolumn{2}{c}{ AC/90/6/TFvte fan } & AC/90/6/TF mvb fan \\
\hline Volume & un-weighted & A-weighted & un-weighted & A-weighted & un-weighted & A-weighted & un-weighted & A-weighted \\
flow & SWL & SWL & SWL & SWL & SWL & SWL & SWL & SWL \\
$m^{3} / s$ & $d B$ & $\mathrm{~dB}(\mathrm{~A})$ & $\mathrm{dB}$ & $\mathrm{dB}(\mathrm{A})$ & $d B$ & $d B(A)$ & $d B$ & $d B(A)$ \\
\hline 8 & 100,1 & 92,5 & 96,7 & 89,3 & 99,7 & 89,1 & 98,6 & 88,1 \\
7 & 96,8 & 92,5 & 96,6 & 87,9 & 96,3 & 87,7 & 94,7 & 86,7 \\
6 & 95,4 & 93,2 & 92,2 & 87,1 & 91,7 & 87,6 & 89,9 & 85,0 \\
\hline
\end{tabular}

An analysis of the efficiency characteristic curves indicates that the four fans tested had essentially similar efficiency characteristics, with similar efficiency levels for all four fans at both the peak pressure and design point. As flow rate is throttled towards stall (approximately $5 \mathrm{~m}^{3} / \mathrm{s}$ ) there is a small increase in efficiency for fans AC90/6/TF, AC90/6/TFvte and AC90/6/TFMVB when compared with the fan datum AC90/6. This improvement enable us to infer that the end-plate control of the blade tip leakage vortex flow influences the overall secondary flow field in the blade tip region, with a resultant small gain in fan efficiency as the fans approach stall. The fan AC90/6/TFMVB exhibits an one per cent improvement in efficiency compared to the fan datum AC90/6 at a flow rate of $6 \mathrm{~m}^{3} / \mathrm{s}$, with a similar efficiency level at a flow rate of $7 \mathrm{~m}^{3} / \mathrm{s}$. As the three fans with end-plates operate at higher flow rates, increasingly off-design their efficiency decreases compared with the fan datum AC90/6.

\subsection{Noise performance}

The analysis of the noise control capability of the MVB endplate focuses on the comparison of the overall acoustic performance measured in accordance with the requirements of ISO 10302 [58], Fig. 10. The four fans studied each had slightly different aerodynamic performance, making it difficult to measure acoustic performance at identical operating point for each fan. The acoustic performance of the four studied fans was measured at the design flow rate of $7 \mathrm{~m}^{3} / \mathrm{s}$. This choice of flow rate resulted in the fans datum AC90/6, AC/90/TF and AC/90/TFvte generating a similar pressure rise. However the fan AC/90/TFmvb generated a significantly higher pressure rise, Fig. 9 A higher pressure developing fan may reasonably be expected to also be a nosier fan, and therefore the descision to test all four fans at the same design flow rate reflects a conservative approach to the comparative analysis of the MVB end-plate performance.

When the narrow-band and A-weighted one-third octave band spectra are studied, a reduction is evident for the fans fitted with end-plates, Fig. 10 We may speculate that the reduction is correlated with noise generation mechanisms found in all classes of decelerating turbomachinery. The end-plates exploit to different extents control over the magnitude of the tip leakage vortices, both in terms of radial footprint and rotational energy content. A consequence of this control is primarily a reduction in tonal noise. In contrast broadband noise reduction may be correlated with mixing enhancement in the blade tip region where the tip vortex develops.
A comparison of the acoustic performance of the four fans studied, Tab. 3 provides and insight into the noise reduction potential of the three end-plate concepts by comparing the un-weighted and A-weighted sound levels at the design and high flow operating points. When comparing the fan AC90/6/TFMVB performance to fan datum AC90/6 there is a $4 \mathrm{~dB}(\mathrm{~A})$ reduction at the $8 \mathrm{~m}^{3} / \mathrm{s}$ high flow rate operating point. This result must be considered within the context of the fan AC90/6/TFMVB delivering a significantly higher total pressure rise than the fan datum AC90/6. This higher total pressure rise may be normalised by taking into account specific noise level $k_{s}$ [61]. A reduction in total pressure rise back to that of fan datum AC90/6 is equivalent to an additional 0.5 to $1.0 \mathrm{~dB}$ reduction in fan AC90/6/TFMVB noise level.

\section{Conclusions}

A new noise-by-flow control concept is presented for the design of blade tip end-plates for subsonic axial fans. The resultant end-plate design is analysed numerically, and the overall performance of fans fitted with the studied end-plates is measured in both aerodynamic and acoustic experimental facilities. In so doing the role of end-plates in the reduction of far-field fan noise is established, and the role of blade tip leakage vortex bursting established.

The noise-by-flow control concept was exploited though the development of a end-plate design procedure that enabled endplate geometry to be created that influenced the momentum transfer into the leakage flow. The variation of end-plate thickness was produced with the specific objective of controlling the chord-wise evolution of the blade tip leakage vortex swirl. The objective in controlling swirl was to control energy transfer from the leakage flow to the blade tip leakage vortex, and in so doing to induce a sequence of subtraction and addition of nearaxis momentum. In so doing the new end-plate design was able via purely passive means to control the tip leakage vortex swirl level, and but first minimising the intensity of the tip leakage vortex and second, ensuring that it did not burst was able to combine the control of tip vortical structures with a reduction in far-field fan noise.

Numerical predictions of the flow field in the blade tip region were used to provide insight into physical principles underpinning the noise-by-flow control concept. Predicted flow streamlines provided a qualitative assessment of the kinematics of the blade tip leakage flow evolution, which is characterised using 
Rossby number, with end-plate thickness being varied to ensure that the near-axis swirl diminution-enhancement result in the tip leakage vortex remaining about a critical value and in so doing does not burst.

Effectiveness of the blade tip end-plate concepts, with either base-line or variable thickness end-plates, was demonstrated via the reduction of fan far-field tonal and broad-band noise. The end-plate designed using the multiple vortex breakdown design procedure was experimentally verified as achieving a noise reduction when compared to a datum fan with no end-plate fitted of $4 \mathrm{~dB}(\mathrm{~A})$ at the high flow operating point.

\section{Acknowledgement}

The present research was undertaken in the context of contract FW-DMA09-11 between Fläkt Woods Ltd and the Dipartimento di Ingegneria Meccanica e Aerospaziale, "Sapienza" University of Rome. The authors acknowledge Stefano Bianchi who was instrumental in the aeroacoustic experimental campaigns.

\section{References}

1 Directive 2005/32/EC establishing a framework for the setting of ecodesign requirements for energy-using products and amending Council Directive 92/42/EEC and Directives 96/57/EC and 2000/55/EC of the European Parliament and of the Council.

2 Baade P, Effects of Acoustic Loading on Axial Flow Fan Noise Generation, Noise Control Engineering, 8(1), (1977), 5-15, DOI 10.3397/1.2832050

3 Wen-Shiang Chiu, Lauchle GC, Thompson DE, Subsonic axial flow fan noise and unsteady rotor force, Journal of Acoustic Society of America, 85(2), (1989), 641-647, DOI 10.1121/1.397589

4 Fukano T, Takamatsu Y, Kodama Y, The effect of the tip clearance on the noise of low pressure axial and mixed-flow fans, Journal of Sound and Vibration, 105(2), (1986), 291-308, DOI 10.1016/0022-460X(86)90158-6

5 Akaike S, Kuroki S, Katagiri M, Noise reduction of radiator cooling fan for automobile. Three-dimensional analysis of the flow between the blades of the fan, JSAE, 22-3, (1991), 79-84.

6 Longhouse R, Control of tip-vortex noise of axial flow fans by rotating shrouds, Journal of Sound and Vibration, 58(2), (1978), 201-214, DOI 10.1016/S0022-460X(78)80075-3

7 Inoue M, Kuroumaru M, Structure of tip clearance flow in an isolated axial compressor rotor, American Society of Mechanical Engineers, Journal of Turbomachinery, 111 (3), (1989), 250-256, DOI 10.1115/1.3262263

8 Storer J, Cumpsty N, Tip leakage flow in axial compressors, Journal of Turbomachinery, 113(2), (1991), 252-259, DOI 10.1115/1.2929095

9 Lakshminarayana B, Zaccaria M, Marathe B, The structure of tip clearance flow in axial flow compressors, Journal of Turbomachinery, 117(3), (1995), 336-347, DOI 10.1115/1.2835667

10 Fukano $\mathbf{T}$, Takamatsu Y, Kodama $\mathbf{Y}$, The effects of tip clearance on the noise of low pressure axial and mixed flow fans, Journal of Sound and Vibration, 105(2), (1986), 291-308, DOI 10.1016/0022-460X(86)90158-6

11 Kameier F, Neise W, Experimental study of tip clearance losses and noise in axial turbomachines and their reduction, Journal of Turbomachinery, 119(3), (1997), 460-471, DOI 10.1115/1.2841145

12 Gad-el-Hak M, Flow Control: Passive, Active, and Reactive Flow Management, Cambridge University Press, 2000, DOI 10.1017/CBO9780511529535

13 Joslin R, Rusell H, Choudhari M, Synergism of Flow and Noise Control Technologies, Progress in Aerospace Sciences, 41(5), (2005), 363-417, DOI 10.1016/j.paerosci.2005.07.002
14 Saiyed NH, Bridges JE, Mikkelsen KL, Acoustics and thrust of separateflow exhaust nozzles with mixing devices for high-bypass-ratio engines, AIAA-2000-1961, ( 2000).

15 Brookfield JM, Waitz IA, Trailing edge blowing for reduction of turbomachinery fan noise, AIAA J Propul Power, 16(1), (2000), 57-64, DOI $10.2514 / 2.5531$

16 Thomas RH, Choudhari MM, Joslin RD, Flow and noise control: Review and assessment of future directions, NASA TM-2002-211631, (April 2002).

17 Takata H, Tsukuda Y, Stall margin improvement by casing treatment - its mechanism and effectiveness, J. of Eng. for Power, 99(1), (1977), 121-133, DOI $10.1115 / 1.3446241$

18 Smith GDJ, Cumpsty NA, Flow phenomena in compressor casing treatment, J. of Eng. Gas Turbines Power, 106(3), (1984), 532-541, DOI 10.1115/1.3239604

19 Thompson DW, King PI, Rabe DC, Experimental and computational investigation on stepped tip gap effects on the flowfield of a transonic axial-flow compressor rotor, Journal of Turbomachinery, 120(3), (1998), 477-486, DOI $10.1115 / 1.2841743$

20 Karlsson S, Holmkvist T, Guide Vane Ring For a Return Flow Passage in Axial Fans and a Method of Protecting it, U.S. Patent 4, 602, (1986), 410.

21 Quinlan DA, Bent PH, High frequency noise generation in small axial flow fans, Journal of Sound and Vibration, 218(2), (1998), 177-204, DOI 10.1006/jsvi.1998.1681

22 Longet CML, Axial flow fan with noise reducing means, US Patent, 2003/0123987 A1, (2003).

23 Mimura M, Axial flow fan, US Patent 6,648,598 B2, (2003).

24 Uselton RB, Cook LJ, Wright T, Fan with reduced noise generation, US Patent 2005/0147496 A1, (2005).

25 Aktürk A, Camci C, Axial flow fan tip leakage flow control using tip platform extensions, Journal of Fluids Engineering, 132(5), (2010), 10, DOI $10.1115 / 1.4001540$

26 Aktürk A, Camci C, Tip clearance investigation of a ducted fan used in VTOL UAVS. Part 1: Baseline experiments and computational validation, ASME paper GT2011-46356.

27 Aktürk A, Camci C, Tip clearance investigation of a ducted fan used in VTOL UAVS. Part 2: Novel treatments via computational design and their experimental verification, ASME paper GT2011-46359.

28 Corsini A, Sheard A, Tip end-plate concept based on leakage vortex rotation number control, J. of Computational and Applied Mechanics, 8(1), (2007), 21-37.

29 Corsini A, Rispoli F, Sheard A, Development of improved blade tip endplate concepts for low-noise operation in industrial fans, Journal of Power and Energy, 221(5), (2007), 669-681, DOI 10.1243/09576509JPE386

30 Ffowcs Williams J, Aeroacoustics, Ann Rev Fluid Mech, 9(1), (1977), 447468, DOI 10.1146/annurev.fl.09.010177.002311

31 Bianchi S, Corsini A, Rispoli F, Sheard A, Detection of aerodynamic noise sources in low-speed axial fan with tip end-plates, IMechE J. of Mechanical Engineering Science, 6(6), (2009), 1379-1392, DOI 10.1243/09544062JMES1277

32 Bianchi S, Corsini A, Rispoli F, Sheard A, Experimental aeroacoustic studies on improved tip configurations for passive control of noise signatures in low-speed axial fans, Journal of Vibration and Acoustics, 131(6), (2009), 061007, DOI 10.1115/1.4000462

33 Corsini A, Sheard A, Rispoli F, Shaping of tip end-plate to control leakage vortex swirl in axial flow fans, Journal of Turbomachinery, 132(3), (2010), 031005, DOI $10.1115 / 1.3145017$

34 Spall R, Gatski T, Grosch C, A criterion for vortex breakdown, Phys. Fluids, 30(11), (1987), 3434-3440, DOI 10.1063/1.866475

35 Escudier M, Confined vortices in flow machinery, Ann Rev Fluid Mech, 19(1), (1987), 27-52, DOI 10.1146/annurev.fl.19.010187.000331

36 Herrada M, Shtern V, Vortex breakdown control by adding near-axis 
swirl and temperature gradients, Physical Review E, 68(4), (2003), DOI 10.1103/PhysRevE.68.041202

37 Jones MC, Hourigan K, Thompson MC, The generation and suppression of vortex breakdown by upstream swirl perturbations, Proceedings of $14^{\text {th }}$ Australian Fluid Mechanics Conference, (2001).

38 Srigrarom S, Kurosaka M, Shaping of delta-wing planform to suppress vortex breakdown, AIAA Journal, 38(1), (2000), 183-186, DOI 10.2514/2.939

39 Srigrarom S, Kurosaka M, Shaping of delta-wing planform to suppress vortex breakdown, AIAA Journal, 38, (2000), 183-186, DOI 10.2514/3.14394

40 Corsini A, Rispoli F, Sheard A, A Meridional Fan, Patent Application, WO/2009/090376, (2009).

41 Uchida S, Nakamura Y, Ohsawa M, Experiments on the axisymmetric vortex breakdown in a swirling air flow, Transactions Japan Society for Aeronautical and Space Sciences, 27(78), (1985), 206-216.

42 Garg A, Leibovic hS, Spectral characteristics of vortex breakdown flowfields, Phys. Fluids, 22(11), (1979), 2053-2064, DOI 10.1063/1.862514

43 Ito $\mathbf{T}$, Suematsu $\mathbf{Y}$, Hayase $\mathbf{T}$, On the vortex breakdown phenomena in a swirling pipe-flow, Nagoya University, Faculty of Engineering, Memoirs, 37, (1985), 117-172.

44 BS 848-2.6:2000, 2000, ISO 10302:1996., Fans for general purposes. Methods of noise testing.

45 Corsini A, Sheard A, Rispoli F, Aerodynamic Performance of blade tip end-plates designed for low-noise operation in axial flow fans, Journal of Fluids Engineering, 131(8), (2009), 081101, DOI $10.1115 / 1.3026723$

46 Leibovich S, Wave propagation, instability, and breakdown of vortices, In: Vortex Motion, 1982, pp. 50-67, DOI 10.1007/978-3-663-13883-94

47 Rains DA, Tip clearance flows in axial flow compressors and pumps, Dissertation (Ph.D.), California Institute of Technology, (1954), http:// resolver.caltech.edu/CaltechETD: etd-04152003-112816

48 Lakshminarayana B, Methods of Predicting the Tip Clearance Effects in Axial Flow Turbomachinery, J. of Basic Engineering, 92(3), (1970), 467482, DOI $10.1115 / 1.3425036$

49 Wadia A, Booth T, Rotor-Tip Leakage: Part II-Design Optimization Through Viscous Analysis and Experiment, ASME Journal of Engineering for Power, 104(1), (1982), 162-168, DOI $10.1115 / 1.3227245$

50 Corsini A, Rispoli F, Santoriello A, Tezduyar T, Improved discontinuitycapturing finite element techniques for reaction effects in turbulence computation, Comput. Mech, 38(4-5), (2006), 356-364, DOI 10.1007/s00466-006$0045-\mathrm{x}$

51 Kirk B, Peterson J, Stogner R, Carey G, libMesh: A C++ Library for Parallel Adaptive Mesh Refinement/Coarsening Simulations, Engineering with Computers, 22(3-4), (2006), 237-254, DOI 10.1007/s00366-006-0049-3

52 Craft TJ, Launder BE, Suga K, Development and application of a cubic eddy-viscosity model of turbulence, Int. J. of Heat and Fluid Flow, 17(2), (1996), 108-155, DOI $10.1016 / 0142-727 X(95) 00079-6$

53 Corsini A, Rispoli F, "Flow analyses in a high-pressure axial ventilation fan with a non-linear eddy-viscosity closure", Int. J. of Heat and Fluid Flow, 26(3), (2005), 349-361, DOI 10.1016/j.ijheatfluidflow.2004.10.002

54 Corsini A, Rispoli F, 'Using sweep to extend stall-free operational range in sub-sonic axial fan rotors, J. of Power and Energy, 218(3), (2004), 129-139, DOI $10.1243 / 095765004323049869$

55 Furukawa M, Inoue M, Saiki K, Yamada K, The role of the tip leakage vortex breakdown in compressor rotor aerodynamics, J. of Turbomachinery, 121(3), (1999), 469-480, DOI $10.1115 / 1.2841339$

56 Guedel A, Scattering of an acoustic field by a free-jet shear layer, AIAA paper 83-0698, (1983).

57 Howe MS, On the absorption of sound by turbulence and other hydrodynamic flows, I M A Journal of Applied Mathematics, 32(1-3), (1984), 187209, DOI $10.1093 /$ imamat/32.1-3.187

58 Fans for General Purposes. Methods of Noise Testing Paper, No. BS 8482.6:2000/ISO 10302:1996, ( 2000 ).
59 Bianchi S, Sheard A, Kinghorn I, Corsini A, Rispoli F, 'Experimental Development of a Measurement Technique to Resolve the Radial Distribution of Fan Aero-Acoustic Emissions, Noise Control Eng, 57(4), (2009), 360-369, DOI $10.3397 / 1.3152578$

60 Leggat LJ, Siddon TE, Experimental study of aeroacoustic mechanism of rotor-vortex interactions, J. Acoustical Society of America, 64(4), (1978), 1070-1077, DOI $10.1121 / 1.382065$

61 Fukano T, Kodama Y, Takamatsu Y, Noise generated by low pressure axial flow fans, III: Effects of rotational frequency, blade thickness and outer blade profile, Journal of Sound and Vibration, 56(2), (1978), 261-277, DOI 10.1016/S0022-460X(78)80020-0 